\title{
System Performance Modelling of a Grid-Connected Photovoltaic System in UiTM, Malaysia
}

\author{
Nurmalessa Muhammad", Nor Zaini Zakaria*, Sulaiman Shaari , Ahmad Maliki Omar ${ }^{*}$ \\ *Faculty of Applied Sciences, Universiti Teknologi MARA, Shah Alam, 40450 Selangor, Malaysia \\ E-mail:nurmalessa@gmail.com,drnzaiza@gmail.com,solarman1001@gmail.com \\ ${ }^{\#}$ Faculty of Electrical Engineering, Universiti Teknologi MARA, Shah Alam, 40450 Selangor, Malaysia \\ E-mail:ambomaliki@gmail.com
}

\begin{abstract}
This paper presents the prediction of grid-connected photovoltaic (GCPV) system installed at Green Energy Research Center, Universiti Teknologi MARA, Shah Alam, Malaysia located at latitude of $2{ }^{\circ} \mathrm{N} 101^{\circ} \mathrm{E}$. By using Mathematical approach and climate variations of Malaysia such as module temperature and solar irradiance, the prediction of power systems performance parameters was analyzed. The parameter of the study is limited to 26 consecutive days with filter data of $80 \mathrm{~W} / \mathrm{m}^{2}$ irradiance. This study conducted by using monocrystalline and polycrystalline solar cell technologies. The actual and the predicted data measurement of these solar cell technologies were analyzed. The empirical models were compared according to the coefficient of determination $\left(R^{2}\right)$ and percentage error. MathCAD software was used in order to calculate the prediction and detail analysis of electrical parameters. Finally, the results show a good accuracy between actual and prediction data.
\end{abstract}

Keywords - photovoltaic; prediction; monocrystalline; polycrystalline; grid-connected photovoltaic (GCPV)

\section{INTRODUCTION}

Lately, several methods that involve in the prediction of the output, the efficiency of the system and the electrical performance optimization for grid connected photovoltaic (GCPV) system. There are varying examples as common as the use of Artificial Neural Network (ANN) [1]-[3], Least Square Support Vector Machine [4] and Grey Model and Markov Chain [5]. This analysis uses the solar irradiance, module temperature and ambient temperature as the inputs whiles the current and voltage as the predicted output.

By referring to the Köppen-Geiger climate classification [6], Malaysia is classified under equatorial rainforest fully humid climate (Af). Malaysia is naturally having climate characteristic features as uniform temperature, high relative humidity and heavy rainfall throughout the year. The annual daily irradiation of 4.21 to $5.56 \mathrm{kWh} / \mathrm{m}^{2}$ [7] with the annual solar irradiation is estimated to be $1,643 \mathrm{kWh} / \mathrm{m}^{2}$. By using Mathematical approach based on fundamental equations, this paper proposed a prediction of PV system output located in Universiti Teknologi MARA, Malaysia.

The proposed method uses electrical data (irradiance, module temperature, and ambient temperature) to forecast the output power. This method is more relevant to predict system performance and could help to confirm the mechanism accuracy of the system GCPV.

\section{MATERIAL AND METHOD}

\section{A. Description of GCPV system}

This research is located in the Green Energy Research Centre (GERC), Universiti Teknologi MARA (UiTM) Shah Alam, Selangor. Fig. 1 and 2 show the PV array of monocrystalline (System 1) and polycrystalline (System 2). For each individual grid inverter, the system is recorded for every 5 minutes by using built-in data logger. The period of this data was recorded for 26 consecutive days. The data analyzed were data of solar irradiation, the temperature of PV module, power, current, and voltage. This system is described in Table 1.

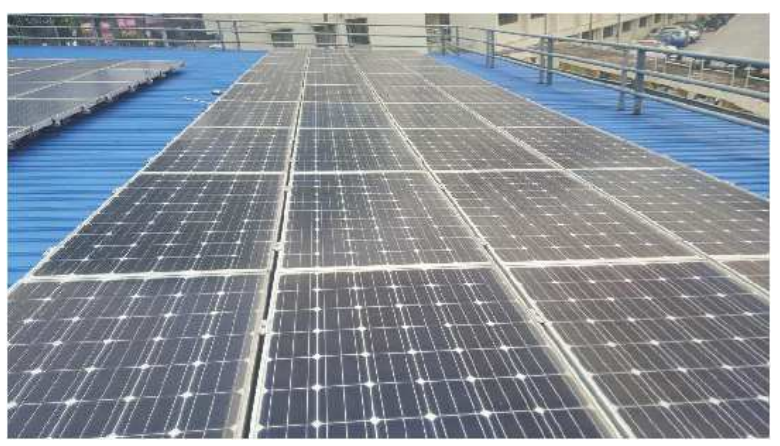

Fig. 1 Monocrystalline PV array (System 1) 


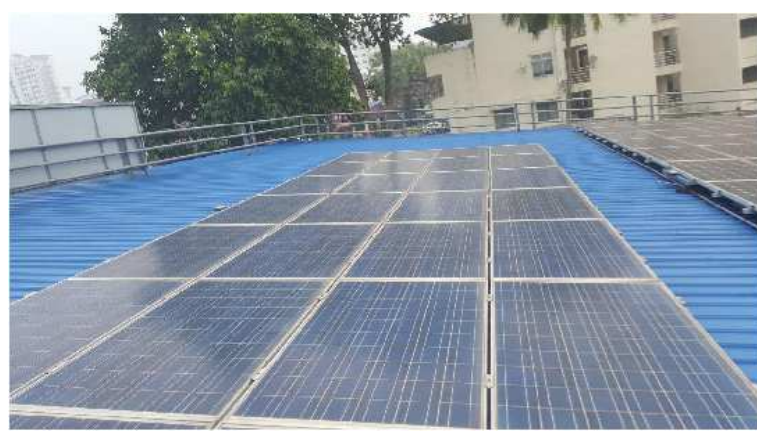

Fig. 2 Polycrystalline PV array (System 2)

TABLE I

DESCRIPTION OF GCPV POWER SYSTEM

\begin{tabular}{|c|c|c|}
\hline Description & System 1 & System 2 \\
\hline $\begin{array}{l}\text { PV module } \\
\text { type } \\
\text { PV model } \\
\text { make \& model }\end{array}$ & $\begin{array}{l}\text { Monocrystalline } \\
\text { Yingli Panda 250 } \\
\text { Wp YL250C-30b }\end{array}$ & $\begin{array}{l}\text { Polycrystalline } \\
\text { Yingli YL235P-29b }\end{array}$ \\
\hline $\begin{array}{l}\text { Parameters } \\
P_{m p}(W) \\
V_{m p}(V) \\
I_{m p}(A) \\
Y_{p m p}\left(\% C^{-1}\right) \\
Y_{\text {imp }}\left(\% C^{-1}\right) \\
f_{\text {dirt }} \\
f_{\text {cable_loss }} \\
f_{\text {mm }} \\
f_{\text {aging }}(\%) \\
\end{array}$ & $\begin{array}{l}250 \\
30.5 \\
8.2 \\
-0.42 \\
0.04 \\
0.97 \\
0.97 \\
0.95 \\
0.97 \\
\end{array}$ & $\begin{array}{l}235 \\
29.5 \\
7.97 \\
-0.45 \\
0.06 \\
0.97 \\
0.97 \\
0.95 \\
0.97 \\
\end{array}$ \\
\hline $\begin{array}{l}\text { Configuration } \\
\text { of PV Array }\end{array}$ & $\begin{array}{l}2 \text { parallel x } 18 \\
\text { series }\end{array}$ & $\begin{array}{l}1 \text { parallel } 12 \text { series } \\
+1 \text { parallel } 11 \\
\text { series }\end{array}$ \\
\hline $\begin{array}{l}\text { Total Capacity } \\
\text { PV Array }\left(W_{p}\right)\end{array}$ & 9000 & 5405 \\
\hline $\begin{array}{l}\text { Efficiency }(\%) / \\
\text { Type of } \\
\text { inverter }\end{array}$ & $\begin{array}{l}\text { Sunny Tripower } \\
\text { STP8000TL } \\
98.3\end{array}$ & $\begin{array}{l}\text { Sunny Boy } \\
\text { SB5000TL } \\
97\end{array}$ \\
\hline $\begin{array}{l}\text { Mounting } \\
\text { Structure Type }\end{array}$ & $\begin{array}{l}\text { Retrofitted on metal } \\
\text { deck }\end{array}$ & $\begin{array}{l}\text { Retrofitted on metal } \\
\text { deck }\end{array}$ \\
\hline
\end{tabular}

\section{B. Mathematical Approach}

Through mathematical approach, the predicted DC Power, DC Voltage, DC Current and AC Power calculations are prepared.

Generally, climate and system parameters contributed the de-rated of the DC Power generated from the PV array. Equation 1 predicts DC Power, $P_{d c_{-} \text {input }}$ which received at the input terminal inverter [8]:

$$
\begin{aligned}
& P_{d c_{-} \text {input }}=P_{m p_{-} s t c} \times f_{t_{-} \text {Pmp }} \times N_{\text {total }} \times f_{\text {dirt_array }} \\
& \times f_{\text {mm_DC }} \times f_{\text {cable_DC }} \times f_{\text {age }} \times \frac{G}{1000}
\end{aligned}
$$

where $P_{m p \_s t c}$ is the PV array maximum power output at Standard Testing Condition (STC). The factors that are considered in equation (1) are $N_{\text {total }}$ referred to the PV modules total number of an array, $f_{\text {dirt }}$ represented as the accumulation of dirt, $f_{\text {cable_DC }}$ represent the factor of cable loss, $f_{m m_{D} D C}$ represented as a factor of module mismatch and $f_{\text {age }}$ represent as solar module aging factor. Equation (2) is a calculation of the temperature factor, $f_{t_{-} P m p}[8]$ :

$$
f_{t_{-} P m p}=1+\left[\left(\frac{\gamma_{P m p}}{100}\right) \times\left(T_{\text {module }}-25\right)\right]
$$

where $f_{t_{-} \text {Pmp }}$ represent as the de-rating factor of the temperature, whilst $Y_{P m p}$ is described as power temperature coefficient $\left(\% /{ }^{\circ} \mathrm{C}^{-1}\right)$ or $(\% / \mathrm{K})$.

In general, the DC voltage generated by the PV array always affected by module temperature which means module temperature has a significant impact on DC voltage. Whilst, as shown in equation (3), solar irradiance only contribute a marginal effect at the DC voltage [8]:

$$
V_{D C_{-} \text {input }}=\left(V_{m p_{-} s t c} \times f_{t_{-} \text {Vmp }} \times N_{\text {series }}\right) \times\left[1+m \ln \left(\frac{G}{1000}\right)\right]
$$

where $V_{D C_{-} \text {input }}$ represented as the voltage maximum power condition output of the PV array at Standard Testing Condition (STC). Meanwhile, the constant, $m$ is to get the desired point and obtained by using curve fitting techniques. In equation (4), a temperature factor is indicated:

$$
f_{t_{-} V m p}=1+\left[\left(\frac{\beta_{V m p}}{100}\right) \times\left(T_{\text {module }}-25\right)\right]
$$

where voltage temperature coefficient is defined as $\beta_{V m p}$ $\left(\% /{ }^{\circ} \mathrm{C}^{-1}\right)$ or $(\% / \mathrm{K})$. There are some situations where the datasheet of PV modules only presents open circuit condition of voltage temperature coefficient, $\beta_{V o c}$. It also can be considered because $\beta_{V m p}$ is equal to $\beta_{V o c}$. $N_{\text {series }}$ represent the PV modules number in series connection. Equation (5) predicts the DC current:

$$
I_{D C_{-} \text {input }}=I_{m p} \times f_{t_{-} \operatorname{Im} p} \times N_{\text {Parallel }} \times f_{m m} \times f_{\text {dirt }} \times \frac{G}{1000}
$$

whereas the current at maximum power of PV array at Standard Testing Condition (STC) is defined as $I_{m p}$ and the PV strings total number that connected in parallel is represented as $N_{\text {Parallel }}$. Whereas, equation (6) can be determined by the temperature factor, $f_{t_{-} \text {Imp }}$ which as:

$$
f_{t_{-} \operatorname{Im} p}=1+\left[\left(\frac{\alpha_{\operatorname{Im} p}}{100}\right) \times\left(T_{\bmod u l e}-25\right)\right]
$$

Referring to equation (1) and (3), DC current is predicted using equation (7):

$$
I_{D C_{-} \text {input }}=\frac{P_{D C_{-} \text {input }}}{V_{D C_{-} \text {input }}}
$$

The common parameters evaluated are the energy yield of PV system, specific yield and performance ratio which represents the overall system performance. The performance parameters of the PV system is determined by solar resources, energy production and the on the whole effect of the system loss.

From the equation (9), the AC energy output of the PV system for both actual and predicted data is calculated:

$$
E_{\text {array }}=\sum P_{\text {AC_output }} \times \frac{t}{60}
$$

where $P_{A C_{-} \text {output }}$ is the calculated for actual and predicted of AC power and the sampling time of PV system is refer as $t$.

The specific yield, $Y_{f_{-} \text {array }}$ is known as the net AC energy 
output per $k W p$ of PV array, in the relationship between the total energy output of the inverter and the size of PV array. To provide the same energy, specific yield represents the number of hours necessary for PV array operating at rated power. To normalize the energy produced relating to the size of the PV system, the specific yield can be resolved using equation (9):

$$
Y_{f_{-} \text {array }}=\frac{E_{\text {array }}}{P_{\text {array_stc }}} \quad\left(k W h k W p^{-1}\right)
$$

The Performance Ratio, $P R_{\text {array }}$ expects the losses of overall effect in a mismatch, efficiency inverter rated output and other losses when switching from DC to AC power. Based on case studies, each year the $P R$ will be reported and this is very useful to identify any incidents of component failure. The performance ratio $P R$ for actual and predicted data is determined by the equation (11) and the acceptable value of $P R$ according to a source [8] must be more than $70 \%$, referring to Malaysia climate.

$$
P R_{\text {array }}=\frac{E_{\text {array }}}{E_{\text {ideal }}}
$$

where $E_{\text {ideal }}$ is the PY array at STC ideal energy output which could be drawn from equation (12) [8]:

$$
E_{\text {ideal }}=P_{\text {array }_{-} S T C} \times \mathrm{PSH}_{h}
$$

where $\mathrm{PSH}_{h}$ is the value of peak sun hour for the particular tilt angle over the period of occurrence in hours $(h)$.

To measure the fitness of the model, the coefficient of determination, $R^{2}$ is proposed. In this study, $R^{2}$ measures the goodness of fit in the sense of comparing Actual values and Predicted values. In general, as the higher $R^{2}$, the better model fits the data where 0 noted as extremely poor fit and $100 \%$ noted as perfect fit [9].

Equation (12) shows the calculation of the percentage error to compare the prediction value with an actual value. It will prove how close the prediction (manufacturer value) was to the actual value [10].

$$
\text { Error }_{\text {percent }}=\sum\left(\frac{\text { Prediction-Actual }}{\text { Actual }}\right) \times 100 \%
$$

\section{Power losses in DC side of the system}

There are several factors that lead to an overall loss that occurs on the DC side of GCPV system. Part of this loss was due to the PV module itself and apart from that caused by climatic conditions. "Capture Loss $\left(L_{c}\right)$ " is defined as the losses of power on the DC side of the GCPV system. This situation stems from the operating cell's temperature [11] involved, the level of solar irradiance, PV shading, and the angle of incidence of sunlight (AOI) [12].

The capture losses [13], [14] are a good indicator of failures occurring on the DC side of the photovoltaic systems and given by the following equation (15) [14]:

$$
L_{c}=Y_{r}-Y_{a}
$$

$L_{c}\left(\mathrm{kWh} / \mathrm{kW}_{\mathrm{p}} \mathrm{d}\right)$ where $Y_{r}\left(\mathrm{kWh} / \mathrm{kW}_{\mathrm{p}} \mathrm{d}\right)$; is the reference yield, and is defined as the total in-plane solar irradiance $H_{i}$ $\left(\mathrm{kWh} / \mathrm{m}^{2}\right)$ divided by the array reference irradiance $G_{0}(1$ $\mathrm{kW} / \mathrm{m}^{2}$ ), given as [14]:

$$
Y_{r}=\frac{H_{i}}{G_{0}}
$$

$Y_{a}\left(\mathrm{kWh} / \mathrm{kW}_{\mathrm{p}} \mathrm{d}\right)$ : is the array yield defined as the energy $E_{D C}(\mathrm{kWh})$ produced by the PV array over a defined period (for example one day, one month or one year) divided by its nominal power $P_{0}(\mathrm{~kW})$. The array yield is given by Kymakis (17) [14]:

$$
Y_{a}=\frac{E_{D C}}{P_{0}}
$$

\section{RESULTS AND DISCUSSION}

In this section, the performance of PV array, inverter, and the whole grid-connected PV system are presented.

\section{A. The performance of $P V$ array}

Fig. 3 and 4 show the results comparing the actual and prediction output generated by DC power from System 1 (monocrystalline) and System 2 (polycrystalline) PV modules. As referred to the equation of linear trend, the independent variables, $x$ represented by solar irradiance, while actual and predicted data of DC Power represented as $y$ variables. Both graphs show as solar irradiance increased the output of DC power also increased. As observed, the trend line of actual is slightly higher than the predicted trend line.

From Table 2, the coefficient determination $R^{2}$ shows more than $90 \%$ a significant positive correlation between actual and prediction data of DC power. Furthermore, the predicted data percentage error of System 2 (Polycrystalline)

\begin{tabular}{|c|c|c|c|c|c|}
\hline & & $\begin{array}{c}\text { DC } \\
\text { Power } \\
(\%)\end{array}$ & $\begin{array}{c}\mathrm{DC} \\
\text { Voltage } \\
(\%)\end{array}$ & $\begin{array}{c}\text { DC Curren } \\
(\%)\end{array}$ & $\begin{array}{l}\mathrm{AC} \\
\text { Power } \\
(\%)\end{array}$ \\
\hline \multirow{3}{*}{ 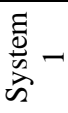 } & $\mathrm{R}^{2}$ (Actual) & 93.0 & 79.89 & 92.5 & 93.6 \\
\hline & $\mathrm{R}^{2}$ (Predict) & 99.8 & 85.8 & 100.0 & 99.8 \\
\hline & Error & 21.723 & 10.069 & 20.131 & 26.998 \\
\hline \multirow{3}{*}{ 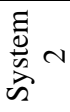 } & $\mathrm{R}^{2}$ (Actual) & 93.2 & 91.66 & 95.0 & 94.9 \\
\hline & $\mathrm{R}^{2}$ (Predict) & 99.7 & 90.33 & 100.0 & 99.7 \\
\hline & Error & 0.195 & 4.841 & 9.228 & 2.212 \\
\hline
\end{tabular}
is performed much better than System 1 (Monocrystalline). Therefore, it could be assumed that fault has occurred in System 1.

\begin{tabular}{|c|c|c|}
\hline & & $\begin{array}{c}L_{c} \\
\left(\mathrm{kWh} / \mathrm{k} W_{\mathrm{p}} \mathrm{d}\right)\end{array}$ \\
\hline \multirow{3}{*}{ 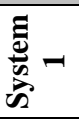 } & Actual & 41.579 \\
\hline & Predict & 26.144 \\
\hline & Error (\%) & 37.122 \\
\hline \multirow{3}{*}{ 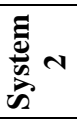 } & Actual & 27.184 \\
\hline & Predict & 27.35 \\
\hline & Error (\%) & 0.612 \\
\hline
\end{tabular}

TABLE II

The Absolute Percentage DifFerent of Determination COEFFICIENT, R2 AND PERCENTAGE ERROR

TABLE III

CAPTURE LOSS, LC OF GCPV SYSTEM

Table 3 shows the value for Capture Loss, $L_{c}$ of both systems. $L_{c}$, as described above is the indicator of failures occurring on the DC side. The percentage error of both systems indicated that System 1 has the highest percentage 
error which could leave an indicator the DC side of the PV system represents a fault.

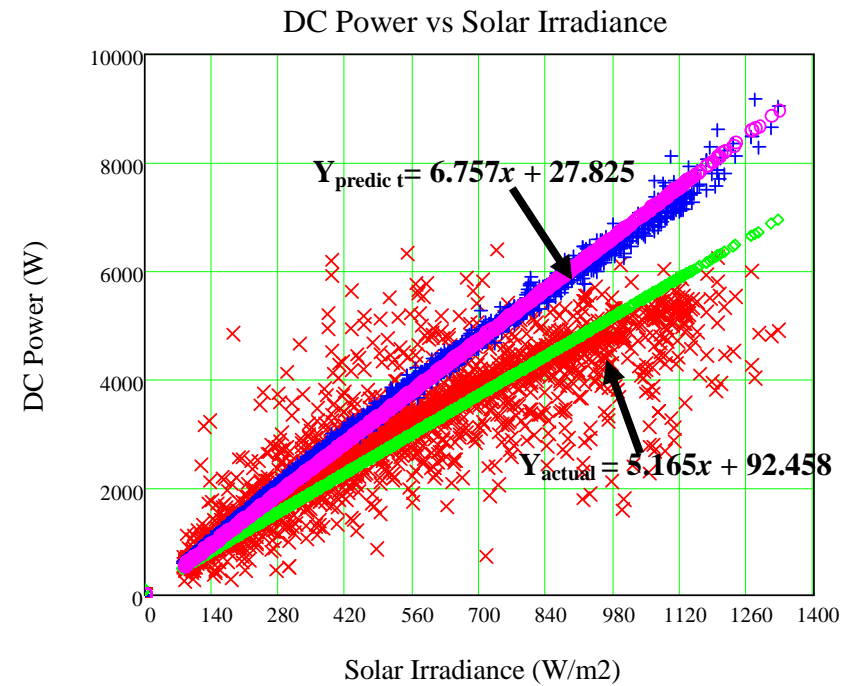

$$
\begin{aligned}
& \times \times \times \text { Pdc_actual } \\
& \text { +++ Pdc_predict } \\
& \diamond \diamond \diamond \text { Y_actual } \\
& \diamond \diamond \diamond \text { Y_predict }
\end{aligned}
$$

Fig. 3 DC power versus solar irradiance (Monocrystalline)

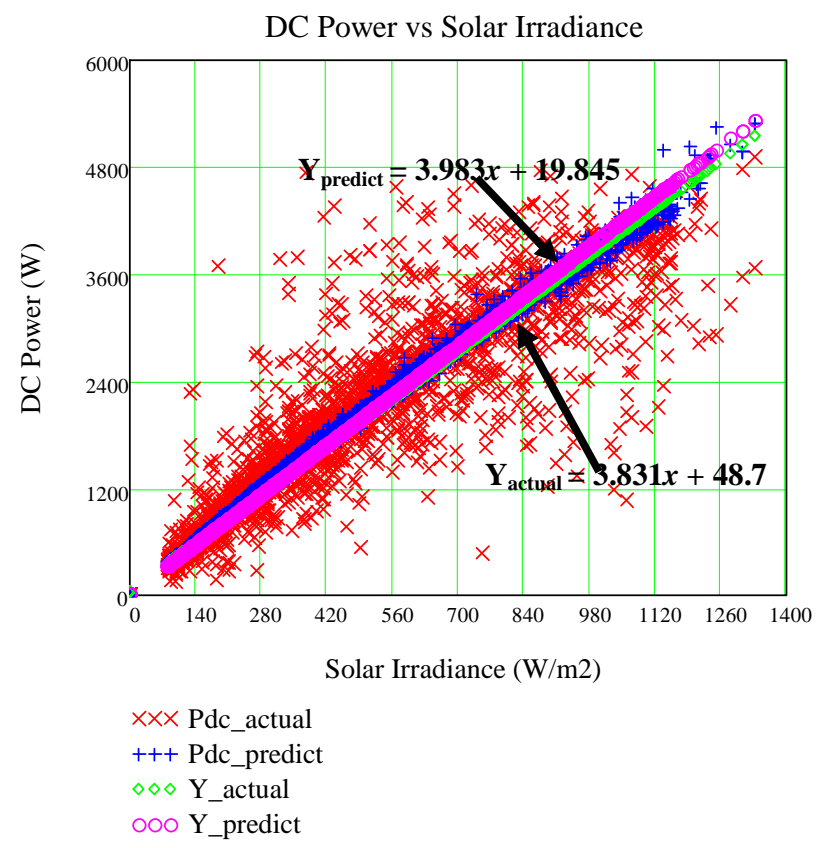

Fig. 4 DC Power versus solar irradiance (Polycrystalline)

Fig. 5 and 7 shows the comparison between the predicted and actual data of DC voltage on each case study. From the linear trend equation, the dependent variable, $y$ is represented by DC voltage. Meanwhile, the temperature of PV module represents the independent variable, $x$. The trend line for the data observed a slightly higher of predicted than actual data. However, the graph also shows that the regression line of actual and predicted data pursue a parallel trend. It was observed that the DC voltage decreases while the temperature of the module increases. SEDA has also been agreed that the optimum solar radiation is filtered in the system is more than $350 \mathrm{~W} / \mathrm{m}^{2}$ as plotted in Fig. 5 and 7, in which up to a constant DC voltage. Referred on the linear trend, $R^{2}$ is observed between $80 \%$ to $85 \%$ for both actual and predicted System 1. Meanwhile, for System 2, $R^{2}$ is examined more than $90 \%$. Furthermore, the error of percentage value was $10 \%$ and 5\% for System 1 and System 2 , respectively.

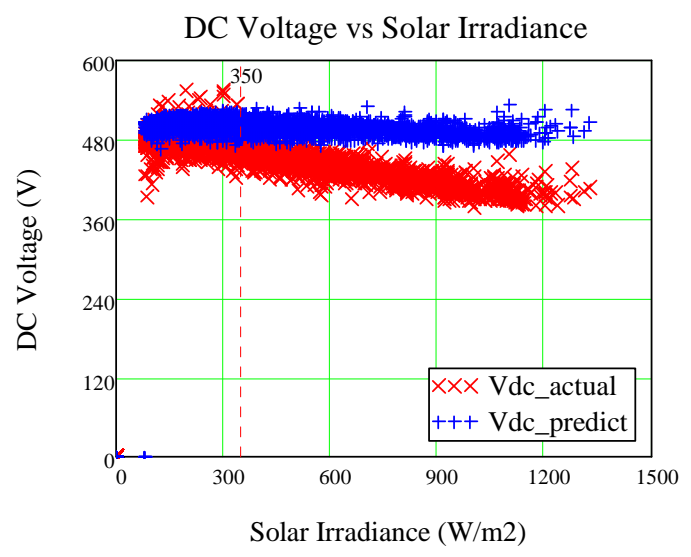

Fig. 5 DC Voltage versus solar irradiance (Monocrystalline)

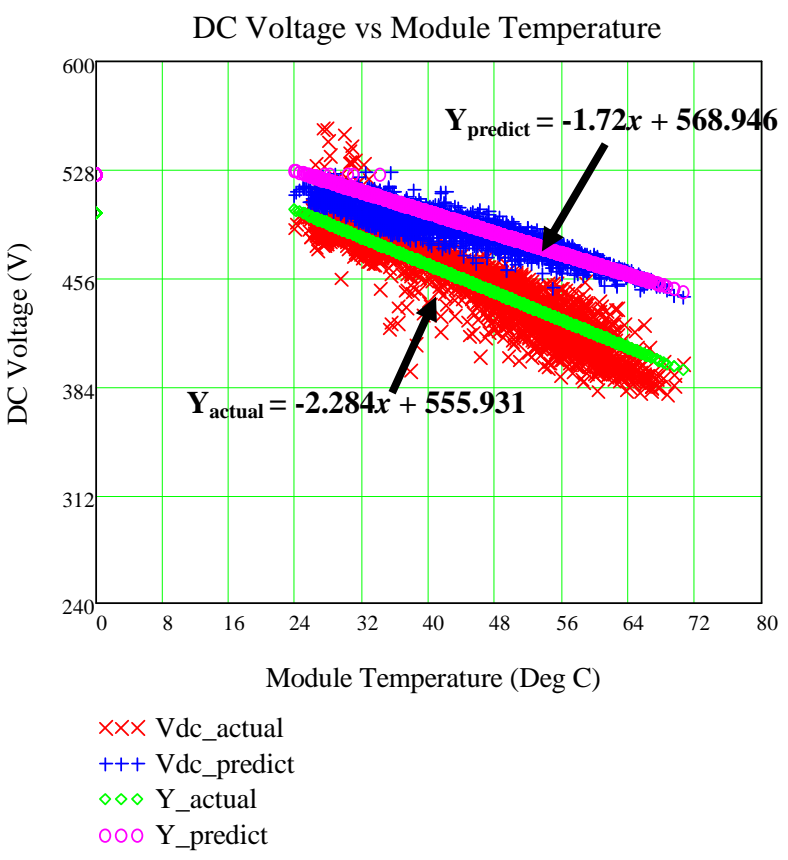

Fig. 6 DC Voltage versus module temperature (Monocrystalline)

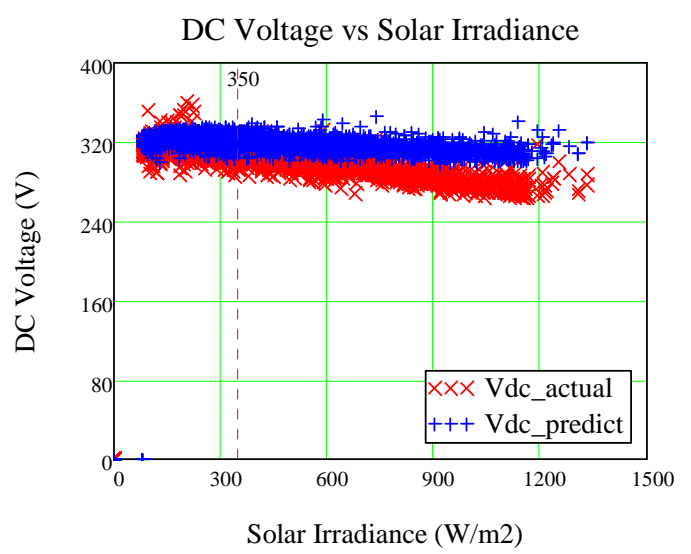

Fig. 7 DC Voltage versus solar irradiance (Polycrystalline) 


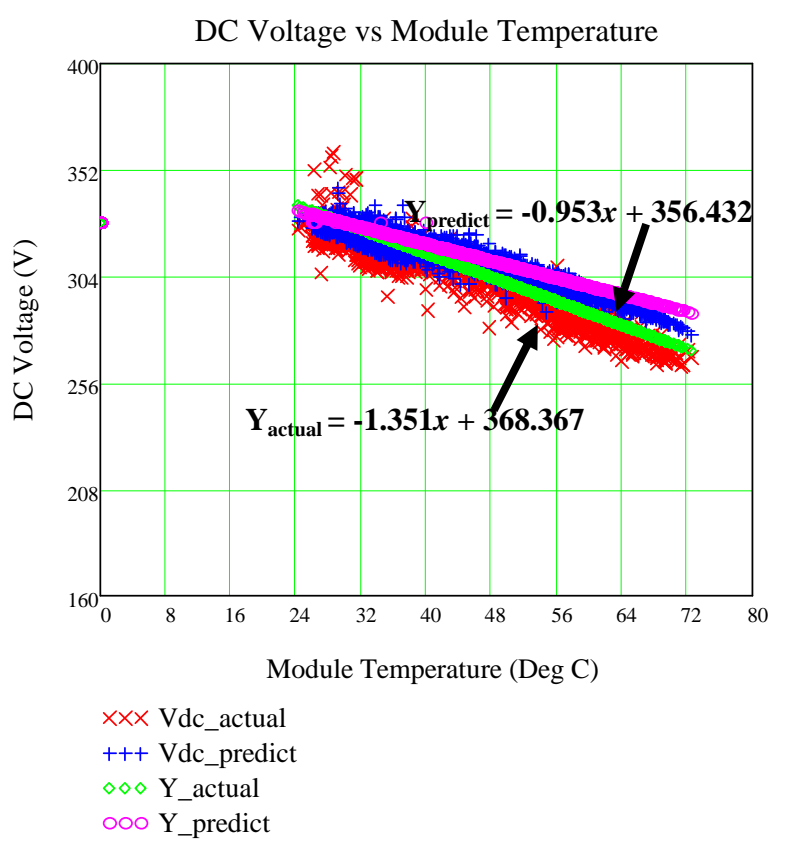

Fig. 8 DC Voltage versus module temperature (Polycrystalline)

Monocrystalline and polycrystalline predicted and actual data of output generated DC current is compared and shown in Fig. 9 and 10. The variables of independent, $x$ represented by solar irradiance and the DC current indicates as $y$ variables. It is observed that the linear line of actual is slightly lowered than a linear line of predicted. On each case study, there is also a clear increasing linear line for both actual and predicted data. Obviously, the DC current is affected by solar irradiance. The coefficient of determination, $R^{2}$ of DC current are close to $100 \%$. Therefore it is clearly shown that fault occurred in DC current of monocrystalline PV systems (System 1).

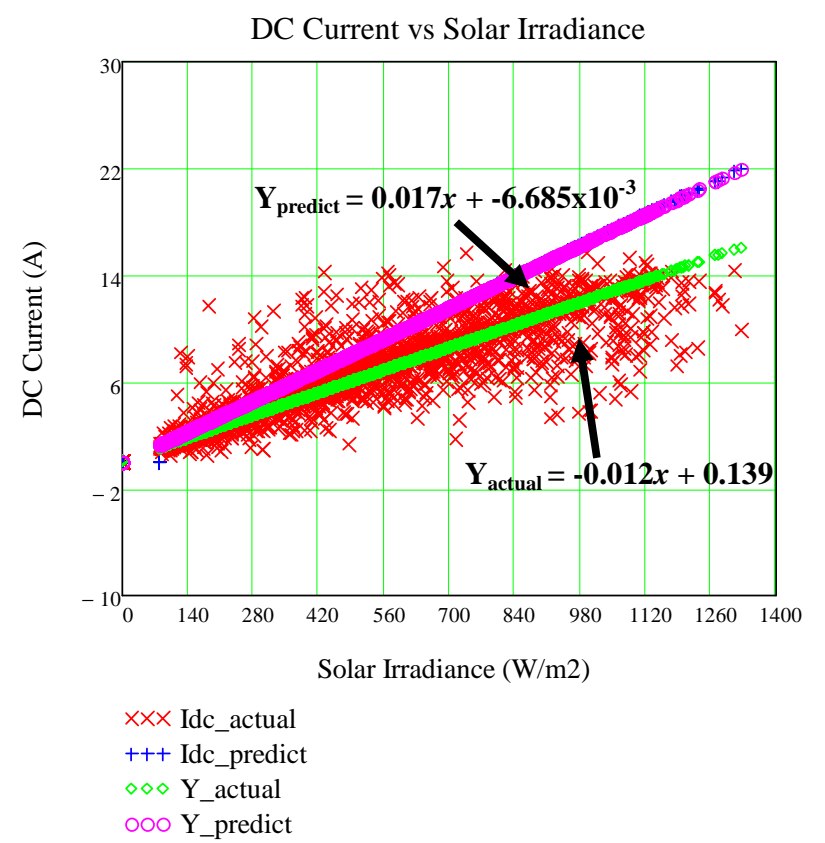

Fig. 9 DC Current versus solar irradiance (Monocrystalline)

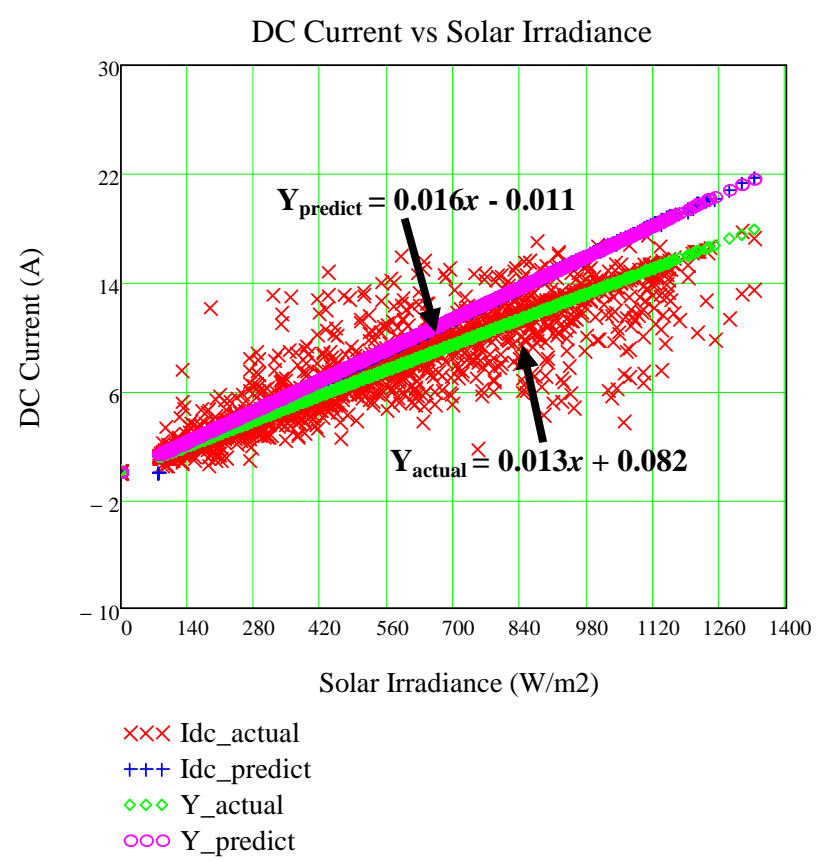

Fig. 10 DC Current versus solar irradiance (Polycrystalline)

Fig. 11 to 14 show the results of output AC power produced from the inverter. The independent variables, $x$ designated as solar irradiance, while the dependent variable $y$ is represented by the actual and predicted of AC power. The finding shows that predicted trend line of System 1 is slightly elevated compares to the linear line of the actual data. However, the linear line of polycrystalline PV system shows that actual and predicted data are almost equal. It also can be seen that from both case studies, the AC power graph has a positive relationship between actual and predicted data. As a function of solar irradiance increased, a significant increase in AC power is also shown by the result of this analysis. Furthermore, based on the result shown, the coefficient of determination for both actual and predicted data was in excellent correlation approaching $100 \%$. However, the percentage error of $\mathrm{AC}$ power shows that for monocrystalline PV system was approaching 27\%. A huge error compares to polycrystalline PV system which only approaching $2 \%$.

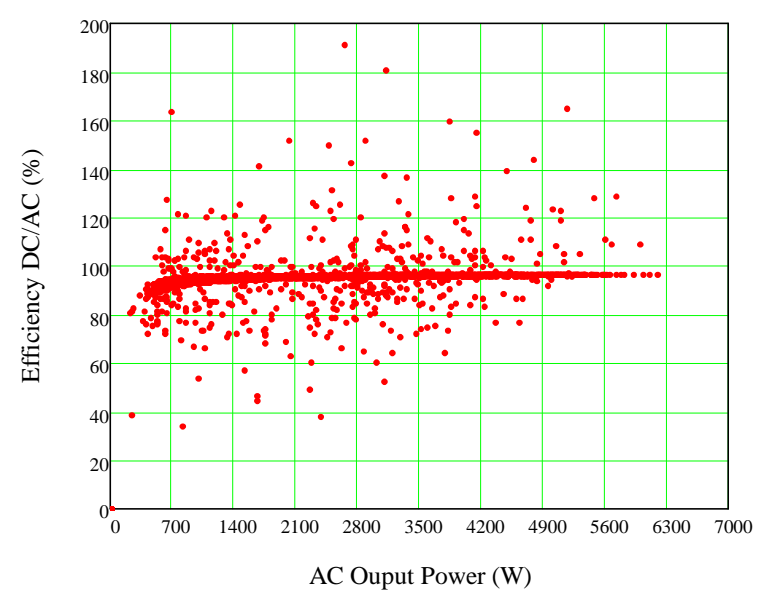

Fig. 11 The relationship between the inverter efficiency and AC output power (Monocrystalline) 


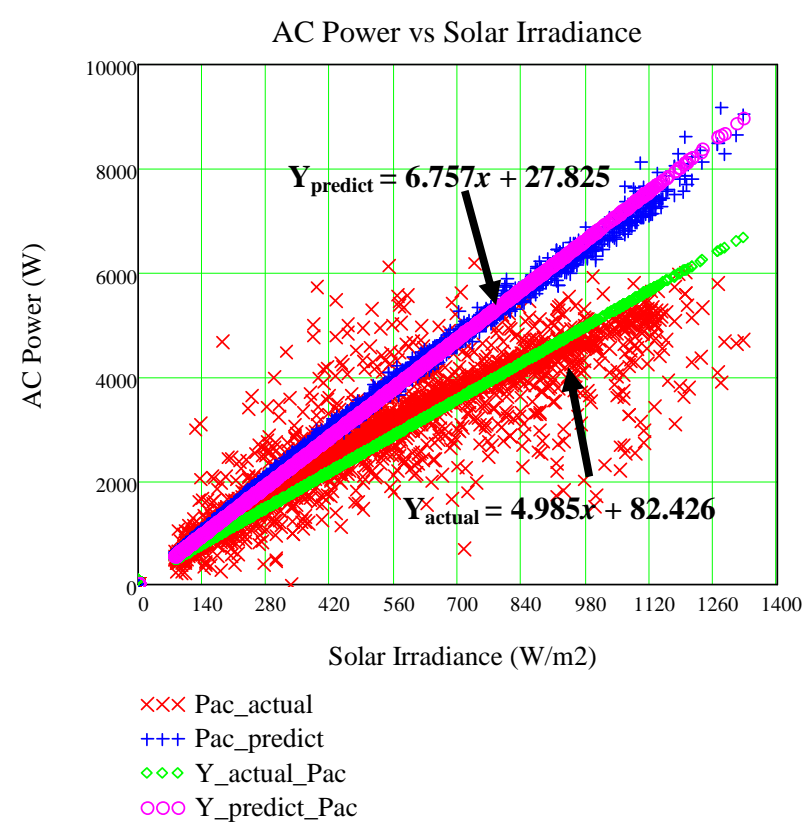

Fig. 12 AC Power versus solar irradiance (Monocrystalline)

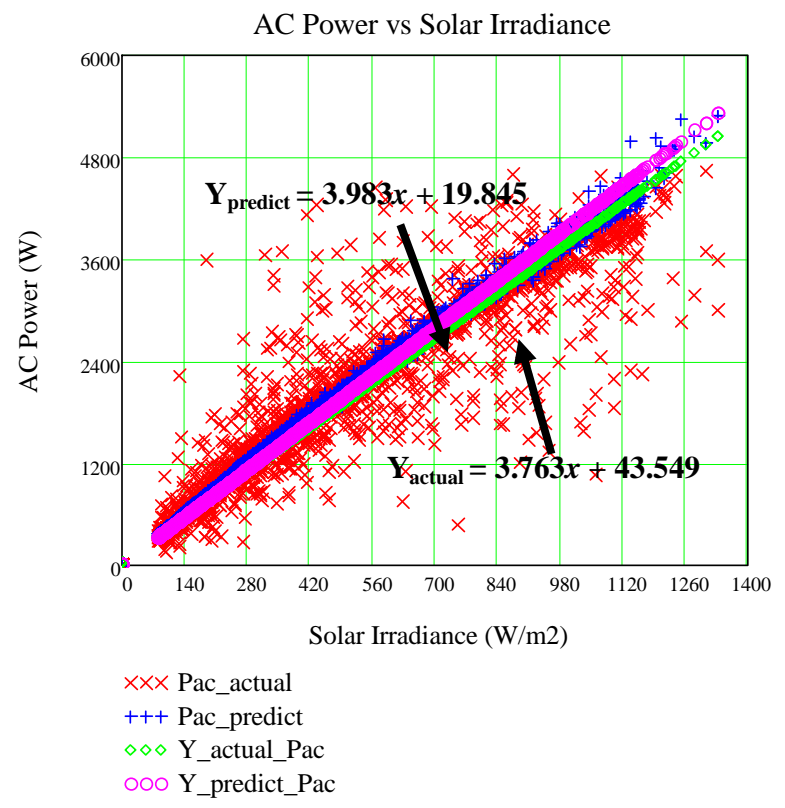

Fig. 13 AC Power versus solar irradiance (Polycrystalline)

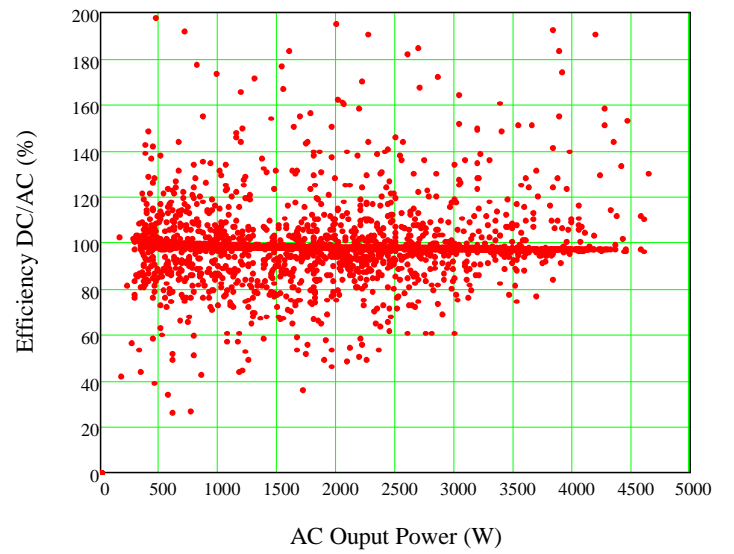

Fig. 14 The relationship between the inverter efficiency and AC output power (Polycrystalline)

\section{B. The Performance of PV Inverter}

The characteristics of the inverter performance are from its operating efficiency behaviour [15]. It can be seen that the actual inverter efficiency was found at 95\% (System 1) and $99 \%$ (System 2). Therefore, it is concluded during the period of monitoring, the inverter was operating close to the rated maximum efficiency. Nevertheless, the inverter is operating within its rated values.

\section{The GCPV System Performance}

Table 4 represents GCPV system performance for both cases. Generally, the specific yield of the study is under surveillance for 26 days in a row under normal value climate of Malaysia. Performance ratio of System 1 for both real and predicted system shows at the rate of $61.2 \%$ and $76.8 \%$, respectively. In contrasts with System 2, the performance ratio for both actual and predicted value is $75.6 \%$. However, for System 1 the PR ratio are lower than the standard value of the requirement in order to proceed on the grid from SEDA Malaysia [16]. Referring to the linear line of all electrical parameters, the linear regression line for the predicted is higher than the actual regression line. Therefore, the percentage of error might be likely contributed from the fault of the DC side of the system. One cause of this error is derating factors like dirt accumulated, $f_{\text {dirt }}$ which is most likely the actual value is higher than 0.97 .

TABLE IV

GCPV SYSTEM PERFORMANCE

\begin{tabular}{|c|l|c|c|c|}
\hline & & $\begin{array}{c}\text { Energy } \\
\text { Yield } \\
(\mathbf{k W h})\end{array}$ & $\begin{array}{c}\text { Specific Yield } \\
\text { (kWh kWp }^{-1} \text { ) }\end{array}$ & $\begin{array}{c}\text { PR } \\
(\%)\end{array}$ \\
\hline \multirow{2}{*}{ System 1 } & Actual & 619.92 & 66.88 & 61.2 \\
\cline { 2 - 5 } & Predict & 778.395 & 86.488 & 76.8 \\
\hline \multirow{2}{*}{ System 2 } & Actual & 460.57 & 85.212 & 75.6 \\
\cline { 2 - 5 } & Predict & 461.216 & 85.331 & 75.7 \\
\hline
\end{tabular}

\section{CONCLUSIONS}

The solar radiation and module temperature is the key factor in influencing the performance of grid connected PV system. In conclusion, this paper shows the mathematical approach to forecast the total output of PV systems based on two case studies that were selected; monocrystalline and polycrystalline for the residential system. Based on the results, the study was compared between actual and predicted electrical performance of grid connected photovoltaic systems. Furthermore, the predicted data and some output results were evaluated using MathCAD software. In future, this study will be evaluated in term of prediction of fault.

\section{ACKNOWLEDGMENT}

The authors would like to thank directly and indirectly the Green Energy Research Center, Universiti Teknologi MARA for the necessary information and data available for study and Kementerian Pendidikan Tinggi for the scholarships grant. 


\section{REFERENCES}

[1] S. Syafaruddin, E. Karatepe, and T. Hiyama, "Controlling of artificial neural network for fault diagnosis of photovoltaic array," Intell. Syst. Appl. to Power Syst., pp. 1-6, 2011.

[2] E. Karatepe, T. Hiyama, S. Syafaruddin, E. Karatepe, and T. Hiyama, "Controlling of artificial neural network for fault diagnosis of photovoltaic array," Intell. Syst. Appl. to, pp. 1-6, 2011.

[3] W. Chine, A. Mellit, V. Lughi, A. Malek, G. Sulligoi, and A. Massi Pavan, "A novel fault diagnosis technique for photovoltaic systems based on artificial neural networks," Renew. Energy, vol. 90, pp. 501-512, 2016.

[4] F. H. Anuwar and A. M. Omar, "Future Solar Irradiance Prediction using Least Square Support Vector Machine," Int. J. Adv. Sci. Eng. Inf. Technol., vol. 6, no. 4, pp. 520-523, 2016.

[5] L. I. Ying-zi, L. Ru, and N. I. U. Jin-cang, "Forecast of Power Generation for Grid-Connected Photovoltaic System Based on Grey Model and Markov Chain," IEEE, pp. 1729-1733, 2008.

[6] M. Kottek, J. Grieser, C. Beck, B. Rudolf, and F. Rubel, "World map of the Köppen-Geiger climate classification updated," Meteorol. Zeitschrift, vol. 15, no. 3, pp. 259-263, 2006.

[7] M. Z. Hussin, M. H. A. Hamid, Z. M. Zain, and R. A. Rahman, "An evaluation data of solar irradiation and dry bulb temperature at Subang under Malaysian climate," Proc. - ICSGRC 20102010 IEEE Control Syst. Grad. Res. Colloq., pp. 55-60, 2010.

[8] A. M. Omar, S. Shaari, and S. I. Sulaiman, Grid-Connected Photovoltaic Power Systems Design. Sustainable Energy Development Authority (SEDA) Malaysia, 2014.
[9] H. Zainuddin, "Modelling of operating temperature for thin film modules for free-standing systems in Malaysia," 2013 IEEE Conf. Clean Energy Technol., pp. 455-460, 2013.

[10] A. Faranadia, A. M. Omar, and Nor Syafiqah Shahirah Mohamed, "Prediction of Grid Connected Photovoltaic power systems performance using mathematical approach," 2014 IEEE 5th Control Syst. Grad. Res. Colloq., pp. 13-18, 2014.

[11] A. R. Amelia, Y. M. Irwan, W. Z. Leow, M. Irwanto, I. Safwati, and M. Zhafarina, "Investigation of the Effect Temperature on Photovoltaic ( PV ) Panel Output Performance," Int. J. Adv. Sci. Eng. Inf. Technol., vol. 6, no. 5, pp. 682-688, 2016.

[12] A. Chouder and S. Silvestre, "Automatic supervision and fault detection of PV systems based on power losses analysis," Energy Convers. Manag., vol. 51, no. 10, pp. 1929-1937, 2010.

[13] S. M. Pietruszko, B. Fetlinski, and M. Bialecki, "Analysis of the Performance of Grid Connected Photovoltaic System," IEEE, pp. 48$51,2009$.

[14] E. Kymakis, S. Kalykakis, and T. M. Papazoglou, "Performance analysis of a grid connected photovoltaic park on the island of Crete," Energy Convers. Manag., vol. 50, no. 3, pp. 433-438, Mar. 2009.

[15] R. A. Rahman, S. I. Sulaiman, A. M. Omar, S. Shaari, and Z. M. Zain, "Performance analysis of a grid-connected PV system at malaysian energy centre, Malaysia," PEOCO 2010 - 4th Int. Power Eng. Optim. Conf. Progr. Abstr., pp. 480-483, 2010.

[16] "SEDA PORTAL." [Online]. Available: http://seda.gov.my/. [Accessed: 02-Dec-2015]. 